\title{
Inductively Coupled Plasma Mass Spectrometer Installation Modifications in \\ a Radioactive Contaminated Laboratory for the Analysis of DOE Radioactive Waste Streams
}

\author{
J. M. Giaquinto \\ J. M. Keller \\ A. M. Meeks
}

Oak Ridge National Laboratory

Oak Ridge, TN 37831-6043

\begin{abstract}
"The submitred manuscript has been authored by a contractor of the U.S. Government under contract No. DE-AC05-96OR22464.

Accordingly, the U.S. Govemment retains a

nonexclusive, royaity-free license to publish or

reproduce the published form of this

contribution. or allow others to do so.

for U.S. Government purposes."
\end{abstract}

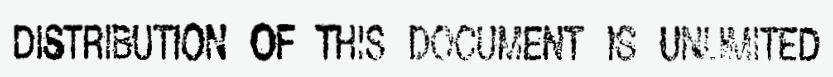

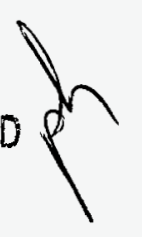

Research sponsored by U.S. Department of Energy,

under contract number DE-AC05-96OR22464 with Oak Ridge National Laboratory, managed by Lockheed Marin Energy Research Corp.

\section{3}




\section{DISCLAIMER}

This report was prepared as an account of work sponsored by an agency of the United States Government. Neither the United States Government nor any agency thereof, nor any of their employees, makes any warranty, express or implied, or assumes any legal liability or responsibility for the accuracy, completeness, or usefulness of any information, apparatus, product, or process disclosed, or represents that its use would not infringe privately owned rights. Reference herein to any specific commercial product, process, or service by trade name, trademark, manufacturer, or otherwise does not necessarily constitute or imply its endorsement, recommendation, or favoring by the United States Government or any agency thereof. The views and opinions of authors expressed herein do not necessarily state or reflect those of the United States Government or any agency thereof. 
Inductively Coupled Plasma Mass Spectrometer Installation Modifications in A Radioactive Contaminated Laboratory for The Analysis of DOE Radioactive Waste Streams

$$
\text { J.M. Giaquinto, J.M. Keller, A.M. Meeks }
$$

Oak Ridge National Laboratory, Radioactive Materials Analytical Laboratory, Bethel Valley Road, Oak Ridge, TN. 37831-6043

\section{ABSTRACT}

The operation and maintenance of a complex analytical instrument such as an inductively coupled plasma mass spectrometer in a radioactive contaminated environment presents unique problems and challenges that have to be considered in the purchasing and installation process. Considerations such as vendor experience, typical radiation levels, sample matrices encountered during sample analysis, instrument accessability for maintenance, and upkeep must be incorporated into the decision process. The Radioactive Materials Analytical Laboratory (RMAL) at Oak Ridge National Laboratory (ORNL) recently purchased and installed an inductively coupled plasma mass spectrometer for the analysis of Department of Energy (DOE) radioactive waste streams. This presentation will outline the purchasing decision, installation of the instrument, and how the modifications needed to operate in a radioactive contaminated laboratory do not significantly impact the daily operation and maintenance requirements of the instrument. Also, a contamination survey of the system will be presented which demonstrates the contamination levels in the instrument from the sample introduction system to the detector.

\section{INTRODUCTION}

The Radioactive Materials Analytical Laboratory is a high level radioactive laboratory located at Oak Ridge National Laboratory (ORNL) that is heavily involved in waste characterization studies of Department of Energy (DOE) underground storage tanks. These studies include a significant amount of analytical method development not only because of the unusual and difficult matrices presented 
by the various type of high level radioactive waste tanks situated on the DOE reservations but also to meet the analytical requirements needed to address such issues as regulatory concerns for waste management, engineering and design data needed for tank remediation efforts, health and safety for the design of risk models, and criticality concerns. Matrix challenges such as caustic $(\mathrm{pH} 12-13)$ samples with high levels of minerals and nitrates (typically molar quantities), high solids content, and high levels of metals such as aluminum, iron, and uranium need to be overcome in order to analyze for other constituents across the periodic table which are present in the waste at low ppm to $\mathrm{ppb}$ levels. The majority of the radioactivity present is normally from the radioisotopes ${ }^{137} \mathrm{Cs}$ and ${ }^{90} \mathrm{Sr}$ (ranging from $10^{4}$ to $10^{6} \mathrm{~Bq} / \mathrm{gm}$ ) but other radionuclides such as those of uranium, plutonium, and long-lived fission products (LLFP) also need to be identified.

An ICP-MS would not only expand the list of metals that could be analyzed by the RMAL and lower their detection limits, but also would allow for more accurate analysis of a range of radioisotopes such as the LLFP's that are difficult to measure with radioactivity counting techniques. ICP-MS would also lower the cost and decrease the turnaround time for the analysis of uranium and plutonium isotopes. The RMAL has been interested in the installation of an ICP-MS in a radioactive laboratory for a number of years to meet the growing need at ORNL for a system installed for radioactive work. Prior to the installation of this instrument, sample aliquots had to undergo expensive and time consuming separation techniques and/or large dilutions to remove or reduce the majority of the sample's activity to meet bench-top radioactivity requirements before being transferred to a non radioactive ICP-MS system. The sample clean-up added additional errors to the analysis and typically the dilutions needed would not allow for the analysis of constituents that were present in the samples at very low concentration levels. 
Presented here is an assessment performed prior to purchase of the instrument, the installation of the instrument, and lastly, a contamination survey taken on the instrument starting from the cones to the detector after one year of operation in a radioactive environment. This paper is intended to provide useful information to other users or laboratories considering the installation of an inductively coupled plasma mass spectrometer for use in a radiochemical laboratory. It is hoped that this information will aid others in making an informed decision when it comes to the planning and design of an ICP-MS laboratory for the analysis of high level radioactive waste and is in no way intended to endorse a single manufacturer.

\section{ASSESSMENT OF LABORATORY AND INSTRUMENT NEEDS}

The radiochemical laboratories at the RMAL are contamination areas that have various containment systems available depending on the type and level of radioactivity present in the samples. The ICPMS would be located in a laboratory where samples can be handled in open faced radiochemical hoods with adjustable sashes. The laboratory is a contamination area but the actual contamination is contained inside the hoods while the general laboratory area is kept free of contamination (based on ORNL Office of Radiation Protection transferable limits). The allowable external radiation limits in these laboratories are $500 \mathrm{mrem} / \mathrm{hr}$ beta-gamma and contamination limits of $10^{6} \mathrm{dpm}$ alpha in the hoods. The radiation levels expected at the instrument itself were expected to be well below the regulated limits after taking into account sample preparation and matrix dilutions. The three drivers used in the decision process were radiation levels and sample matrices encountered during sample analysis, accessability for maintenance and upkeep, and vendor experience in the installation in radiochemical laboratory environments. 
As stated earlier, the radiation levels expected at the instrument would most likely be well below the regulated limits of the RMAL. Typically a 100 fold dilution would be expected during sample preparation ( $0.5 \mathrm{gm}$ of sample in $50 \mathrm{ml}$ acid) and another 100 fold dilution on the sample to handle matrix problems for a total of a 10,000 fold dilution. For any sample that the RMAL analyzes, a 10,000 fold dilution of a $0.5 \mathrm{gm}$ aliquot would be well within the radiochemical hood limits. Typically, the radiation limits are only approached in the sample preparation areas where large quantities of raw material are handled for the various types of sample preparations. Therefore, a decision was made to install an ICP-MS system interfaced with a radiochemical hood. This configuration would be sufficient to meet all radiation protection requirements.

Instrument performance specifications based on typical sample matrices encountered by the RMAL were prepared. These specifications address such concerns as limits of detection, sensitivity, and dynamic range of the instrument. The performance specification which caused the most concern was in the area of signal suppression. As mentioned earlier, a typical ORNL waste tank matrix contains approximately $4 \mathrm{M}$ sodium and up to 1 percent uranium (higher levels of uranium have been detected in certain tanks). These two elements have a large effect on the signal suppression of the plasma and could greatly affect quality of data generated by the instrument. The sodium and uranium concentrations for the signal suppression specification were conservatively determined to allow for minimal dilutions and to prevent the dilution of all elements of interest below the detection limits of the instrument. The specification states that the addition of either $2000 \mathrm{mg} / \mathrm{L} \mathrm{Na}$ or $2000 \mathrm{mg} / \mathrm{L}$ $\mathrm{U}$ will not suppress the intensities of a $100 \mathrm{ug} / \mathrm{L}$ solution of the listed elements more than the percent intensity changes listed in Table 1. 
Table 1

Percent Maximum Allowable Signal Suppression

\begin{tabular}{|c|c|c|}
\hline Element & $2000 \mathrm{ppm} \mathrm{Na}$ & $2000 \mathrm{ppm} \mathrm{U}$ \\
\hline $\mathrm{Li}$ & 30 & 40 \\
\hline $\mathrm{Be}$ & 30 & 40 \\
\hline Co & 20 & 30 \\
\hline $\mathrm{Ni}$ & 20 & 30 \\
\hline In & 15 & 20 \\
\hline $\mathrm{Pb}$ & 10 & 10 \\
\hline $\mathrm{Th}$ & 10 & 10 \\
\hline $\mathrm{U}$ & 10 & - \\
\hline
\end{tabular}

Maintenance and upkeep of the instrument were other important considerations. All of the major maintenance items had to be easily accessible and, when possible, not enclosed within radiological containment. With major electronics and systems located outside of contamination areas servicing of the instrument could be done with reduced radiological precautions and procedures. It was important that the level of containment provide enough protection for the levels of radioactivity expected at the instrument but not so much that the routine operation and maintenance of the instrument would be significantly impacted. Using the typical radiation levels and radioactive isotopes present in ORNL waste tank samples as a guide, it was decided that the radiochemical hood would only house the ion source and sample introduction systems, including the sample and skimmer cones since these components would be the areas most likely contaminated during use. This configuration would provide the necessary ORNL health and safety requirements while leaving the 
major system components open for convenient access.

Lastly, vendor experience was an important issue because of the radiation safety and system performance concerns of interfacing the instrument to a hood. The supplier had to provide evidence of experience including a list of at least five ICP-MS systems interfaced with a radioactive hood enclosing only the area locally around the ICP plasma and sample introduction system. Also, the systems must have been in operation for at least one year and used for the analysis of similar waste.

To support the decision of choosing an interfaced system, the RMAL conducted user surveys of ICP-MS operators. A total of thirteen surveys of ICP-MS users throughout the DOE complexes were completed. Of these surveys, eleven were from users whose instruments were located in contaminated areas and were being used for the analysis of highly radioactive samples. The other two surveys were for instruments that were being used for low level radioactive work on DOE samples but were not located in radiochemical laboratories. These surveys provided useful information for the setup of a radiochemical ICP-MS system that include special features for hood design (appropriate sized hood, rear access panel, hood coatings, etc.). The surveys also allowed us to talk with other researchers and discuss the problems they may have experienced with ICP-MS analysis on waste streams that are similar to our own.

\section{INSTALLATION}

The RMAL purchased a VG Elemental Plasmaquad PQIIplus Turbo ICP-MS in September 1995 and all parts were delivered by January 1996. The installation of the instrument, not including on-site 
testing, lasted approximately 1.5 weeks. The installation was a coordinated effort between ORNL craftsmen and company representatives. The physical setup of the instrument was routine with the exception of the installation of the specially designed hood/detector interface and integrating the instruments exhaust into the existing ventilation lines.

The stainless steel hood was manufactured and fitted to interface with the instrument at the factory so all that was needed on-site was to install the instrument in the laboratory. One challenge was due to the size and weight of the hood itself. The hood measured 70 inches wide and 40 inches deep and required a mini-forklift to transport it into the contamination area laboratory. Special planning and preliminary work was needed to get the forklift into the laboratory, but once the hood was set in place it was a simple procedure to secure the hood to the instrument. Figure 1 is a simple schematic illustrating how the hood is configured with the instrument. As can be seen in the diagram enclosed in the hood are the autosampler, torchbox, and the beginning portion of the mass spectrometer system starting with the sample cone and ending with the slide valve. All other components downstream of and including the lens stack (excluding the extraction lens) is located outside of the hood.

Integrating the instruments exhaust into the existing ventilation required significant planning. Being a high radioactive facility, the RMAL has a specially designed ventilation system. This system. illustrated in figure 2, produces a total air flow of $32,000 \mathrm{cfm}$ and supports a bank of eight radioactive hot cells, a group of high alpha containment gloveboxes, and more than twenty openfaced radioactive laboratory hoods. The laboratory is always maintained at a negative pressure 
relative to the outside environment. All air is supplied to the building via one of two inlet fans and exhausted through two banks of high efficiency particulate air filters. The design of the RMAL HVAC system is such that all air flows from low to high contamination areas. This means that the areas with no potential for contamination are kept at a lower negative pressure than the laboratories, which in-turn are kept at a lower negative pressure than the bank of hot cells. Using this methodology, air will flow through "clean" areas first then into the laboratories before exiting the building. The laboratory ventilation is set such that all of the air is supplied through open grates above each door and exits the lab via the hoods. The concern was that an excessive amount of particulates and potential contaminants (non radioactive) would be directed into the ICP-MS lab and enter into the hood with the samples. This could cause problems with the analysis of trace elements.

Of course the laboratory could never be setup to be a classical clean lab with this type of ventilation flow but was never intended to be used in such a manner. To decrease the volume of air flowing into the ICP-MS hood while maintaining the ORNL flow requirements the lab ventilation system was modified with extra exhaust vents. The exhaust vents provided for an additional conduit for air exiting the laboratory and effectively cut down on the volume of air passing through the ICP-MS enclosure. Once this was completed, it was a simple matter of welding vent lines into the laboratory exhaust line and connecting them to the instrument's exhaust when it was installed.

\section{CONTAMINATION SURVEY}

After one year of operation in a high radioactive lab, a contamination survey was done on the instrument to assay the spread of contamination on the instrument's systems. This survey was performed on various parts of the instrument starting with the sample cone and going to the detector. 
The oils from the two backing rotary pumps were also analyzed. The survey was performed by smearing the areas of interest with a moistened cotton Q-tip. Relative comparison was ensured by tracing an "S" pattern of consistent area when feasible. When this method was not feasible, due to the size or shape of the part, a comparable surface area was smeared instead. The Q-tip was then placed in a scintillation cocktail and counted for beta activity using liquid scintillation. The pump oil was counted using a volume of $100 \mathrm{uL}$ in the scintillation cocktail. Results of the survey are shown in figure 3. It was initially assumed that the sample cone would have the greatest deposit of contamination on it since it is directly in front of the plasma, however, the results show that this is not the case. The plasma actually "burns" the sample cone clean. Most likely there would be a radial pattern of contamination spreading outward from the cone across the expansion chambers face but this area was not included in the survey. As can be seen the part with the highest contamination was the skimmer cone which is caused by the plasma exit gases expanding across its surface. The majority of the contamination is maintained within the hood enclosure with a little detected on the photon stop, which although physically located outside of the hood boundary can only be accessed from inside of the hood. No contamination was detected on the detector or in the pump oil. This survey appears to show that partial containment is adequate for the instruments application.

Initially, there was some concern over the cleaning of the contaminated cones and glassware of the instrument. RMAL had discussed with other users the different options that were available and which ones were best for contaminated components. For the cones, the easiest option was to use them until they needed to be changed rather then dispose of the old ones and replace them with new ones. We did not feel that discarding the cones were necessary and instead chose to soak the cones 
in a dilute cleaning solution in the hood for a number of weeks prior to cleaning. When the cones are removed for cleaning at the end of the soaking period the detectable activity on them is only slightly above background. From this point the cones are cleaned on the benchtop using precautions for environmental samples. The soaking step not only leaches the majority of the contamination from the cones but also loosens the other deposits making the cleaning of the cones much easier. The glassware is cleaned in a similar fashion by first leaching in $20 \%-30 \% \mathrm{HNO}_{3}$ in the hood followed by final cleaning on the benchtop.

\section{CONCLUSION}

A great deal of forethought and research has gone into the purchase and installation of the instrument and the ICP-MS configuration chosen with partial containment has proved to be an extremely effective setup. The containment provides the necessary protection without hindering the daily operation or maintenance of the system. The instrument has performed well in a radioactive environment and has greatly increased the capabilities of the RMAL. 
Figure 1

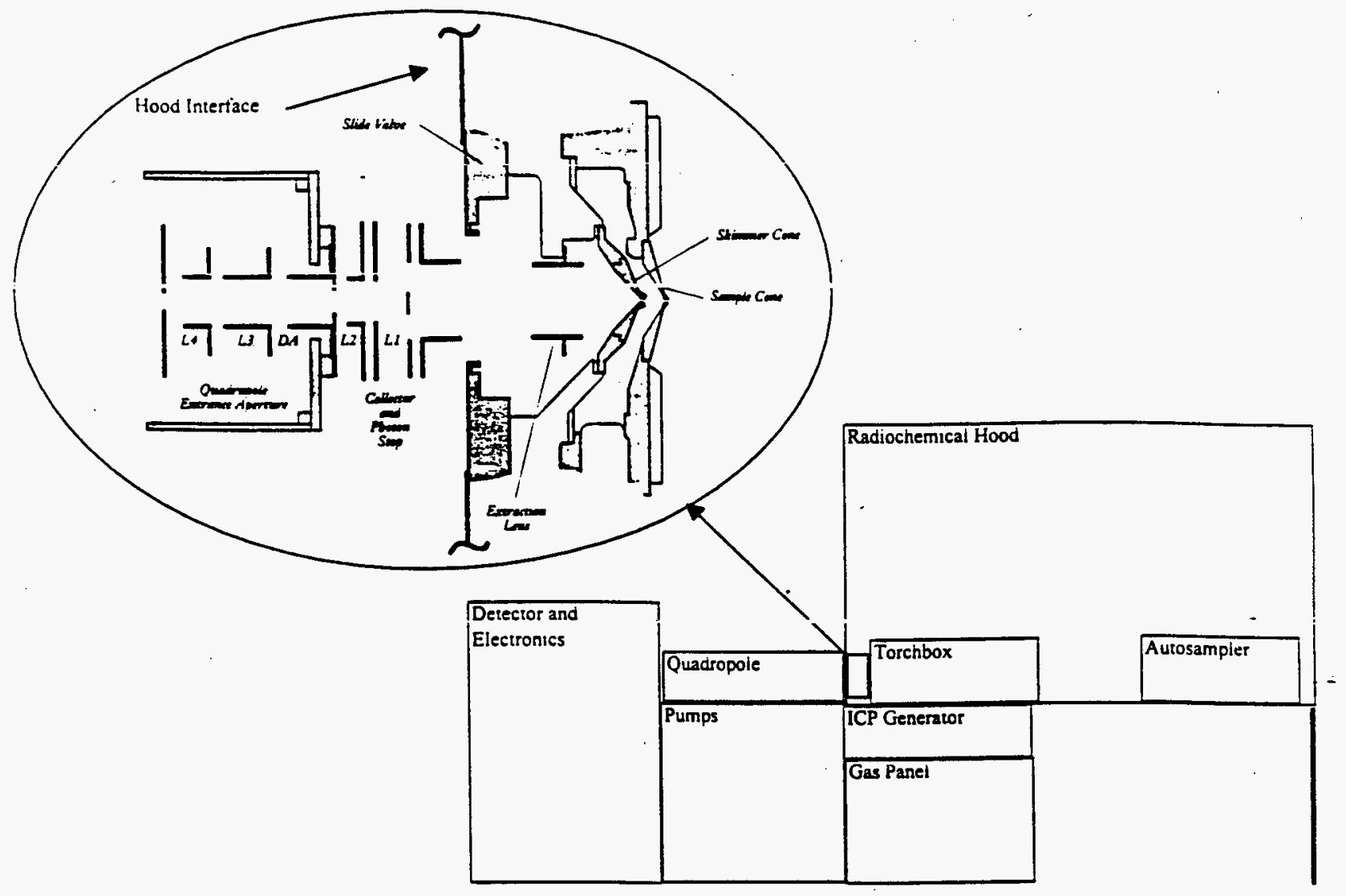


Beta Activity (DPM)

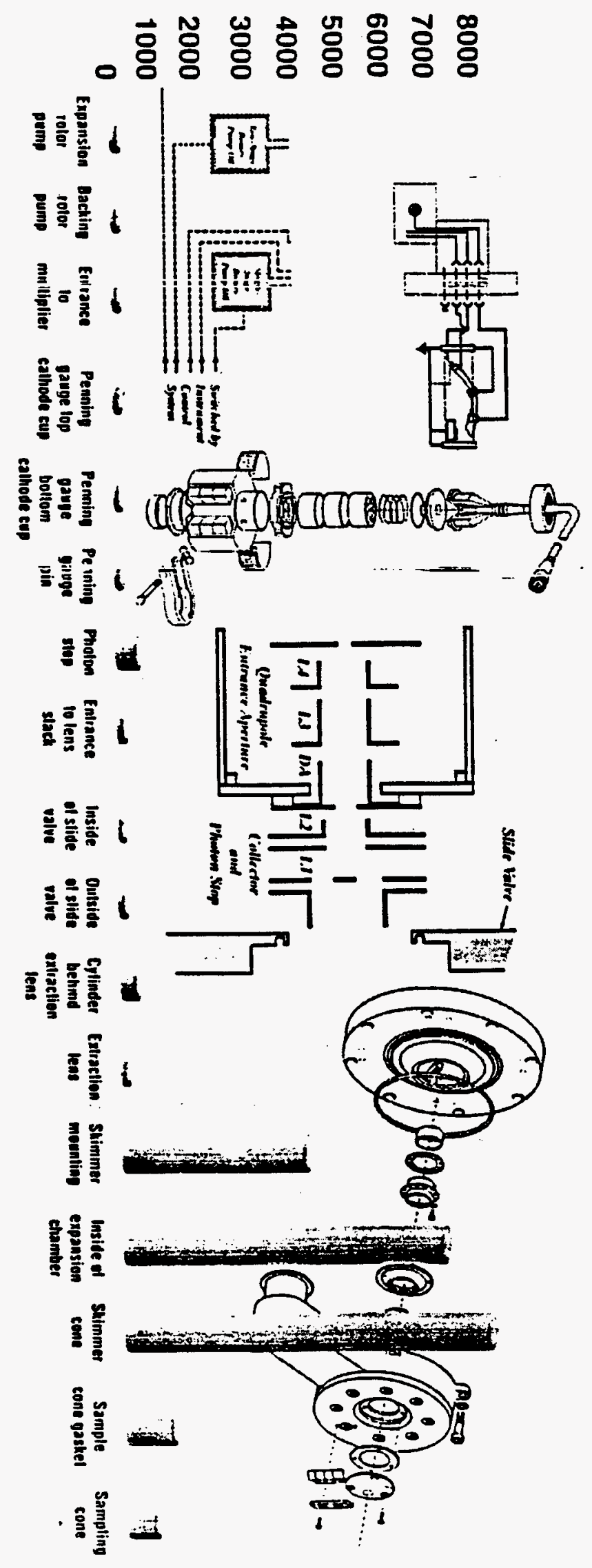

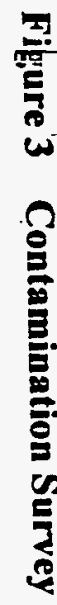




\section{M97008440}

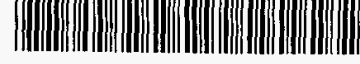

Report Number (14) CONF $-970424--18$

Publ. Date (11) $\frac{199704}{D O E, X F}$
Sponsor Code (18)
UC Category (19) 